\title{
Contribution of Virtual Classrooms to the Personal Learning Environments (PLE) of the students of the Career of Informatics Applied to Education of National University of Chimborazo
}

\author{
Patricio Humanante Ramos \\ Faculty of Education, Humanities and Technology \\ National University of Chimborazo \\ Av. Eloy Alfaro \& 10 de Agosto - Riobamba (Ecuador) \\ (593) 326281152628211 \\ phumanante@unach.edu.ec
}

\author{
Francisco J. García-Peñalvo \\ GRIAL Research Group, \\ Educational Research Institute, University of \\ Salamanca \\ fgarcia@usal.es
}

\begin{abstract}
The incorporation of Information Technology and Communication in education has ensured new learning environments, such as virtual classrooms present today in most Ecuadorian universities, both for distance education or online or to complement classroom education whose duality is known as B-Learning. This is the case of the National University of Chimborazo, Public Higher Education Institution of the Ecuador, which five years ago has begun to gradually integrate these new computing learning's resources. The present study investigates the use of virtual classrooms as tools constitute student's Personal Learning Environments (PLE) in the career of Informatics Applied to Education, where the involved students are studying in the annual mode National University Chimborazo Ecuador. The main results of the study we can mention that in the career in question, there is an increasing the number of subjects that support virtual classrooms for classroom teaching, but learning occurs both in and out of these new learning environments, thus, Web 2.0 tools are important in these processes either to access, process, publish and share resources and content. Finally, we believe that this study is the starting point for future research on the relevance, impact, effectiveness, etc. incorporating the VLE in addition to university teaching as well as on relations and possibilities of integration between LMS and PLEs and latest topics as mobile learning and mobile PLEs.
\end{abstract}

\section{Categories and Subject Descriptors}

K.3.1 [Computers and Education]: Computer Uses in Education - collaborative learning, computer-assisted instruction (CAI), computer-managed instruction (CMI), distance learning.

\section{General Terms}

Human Factors

\section{Keywords}

e-Learning; Information Technology and Communication (ICT); Personal Learning Environments (PLE); Virtual Learning Environments (VLE); Higher Education; Virtual Classrooms.

\section{INTRODUCTION}

The integration of information technology and communication in the field of education has enabled redesign scenarios which produce the teaching-learning process, which has caused an increasingly small barrier between classrooms, semi-face and virtual education and at the same time, between formal, non-formal and informal learning [2], where the roles of teacher and student must change as Salinas stated [19]. In this way, a revolution has occurred in the way we conceive learning experiences compared to the way it was done before [11].

It is also important to note that globally there is a massive incorporation of LMS (Learning Management Systems) platforms in teaching practice. For example, in Spain, the $91.78 \%$ of universities use virtual campus platforms for both proprietary based and free software based, where the participation of the tool Open Source Moodle corresponds to 53.30\% [17]. In addition, as of the date of the preparation of this research, the Moodle website recorded 81, 294 sites and 69,484,250 users distributed in 233 countries [16].

On the other hand, it is also clear that learning has an individual dimension, because each person is unique, with his own interests, limitations and capabilities, so it requires that the knowledge assimilation process be personalized, therefore, giving rise to the need to propitiate Personal Learning Environments (PLE), which is "... the set of tools, data sources, connections and activities that each person uses effectively to learn" [2]. 
At the National University of Chimborazo, a public educational institution located in Riobamba, a city situated $165 \mathrm{~km}$ south of Quito, capital of Ecuador, the process of incorporating the virtual classroom to classroom teaching, environments to achieving the type B-learning, which combines classroom lectures and independent work of students mediated by technology, was begun 5 years ago.

These new educational areas, recreated on Learning Management Systems or LMS, are mostly limited to the simple explanation of content, and many of them also lack clearly defined methods, and specific strategies for this new type of training [11], which leads to wasting the potential in terms of the interaction offered by the Information Technology and Communication (ICT), as personalization. Furthermore, while it is known that formal education could end with the degree, but the human learning continues throughout life. The educational challenge is to train professionals who are prepared to solve tasks that are not current [7]. In the case of computation, the situation is very clear, because the level of updating software packages is continuous and, although students master certain tools, these may already be obsolete when they begin to work in their professional practice and have to work with new software, programming languages, design tools, etc., perhaps very different from those studied in the curriculum.

According to the above, is very important of making a diagnostic use of virtual classrooms as tools constitutive of Personal Learning Environments of students who are studying in annual modality in career Informatics Applied to Education, in the Chimborazo National University.

The theoretical base of this research is included in Sections 2 and 3. The methodology applied in Section 4. Section 5 presents the results and finally the conclusions are presented in Section 6.

\section{E-LEARNING}

It begins presenting some of the most relevant definitions of the concept of e-learning in the literature. As Cabero posed [4], there are a number of terms which refer to the subject at hand: electronic learning, e-learning, online learning, virtual learning, among others, so there are various definitions and approaches that are proposed by the authors. So one can briefly distinguish some perspectives, on the one hand, which can be understood as a training strategy to solve different problems, such as access to education from distant geographic locations, or the need for training and continuous improvement, etc.

It can also be seen as a training tool from conception and development, as suggested by García-Peñalvo [10], with a part pedagogical that responds to models and patterns pedagogically defined and a part technological where the teaching-learning process flow over an infrastructure of software applications based on Web.

On the other hand, there is the approach Jolliffe, Ritter, \& Stevens [15], who add to the concept of this type of learning the distribution, access and exchange, through a web server, a browser and communication protocols as TCP / IP and HTTP respectively. But it also opens the possibility for other resources such as files via FTP, telephony and CD-Rom, which does not limit the concept to prominence of internet only when talking about e-learning, but includes any process, task or educational activity that uses electronic resources, so they are understood to be those that handle digital information.

Is important to add, mentioned by Garcia Peñalvo [10], who proposes in its definition that e-Learning processes, which should suit the 'skills, needs and availability "of each student and" ensure collaborative learning environments by using tools of synchronous and asynchronous communication, so as to enhance in short, the process of competency-based management ", since in this way highlights the potential of e-Learning in terms of personalization of teaching and collaborative learning.

\subsection{Learning Management Systems}

There are common terms to refer to Learning Management Systems (LMS), such as: Content Management Systems - CMS, Virtual Platforms, Virtual Classrooms, etc., however Miguel Zapata [22] manifests: " A learning platform or an learning management system in a network, is a informatics and telematics tool, organized in function of formative targets of integral form and a principles of intervention psycho-pedagogical and organizative". You can see in this definition the importance of formatives objectives and dimensions psychopedagogical and organizative. In addition, it should be emphasized also that the part informatics would be the structure from which they designed the learning process, so that the features and functionality of this software should be taken very considered, as well as their adequate performance and the graphical interfaces user as a means of interaction between the user and technology.

At present there are a large number of such tools, of commercial software or free software; within which to include: Moodle, aTutor, Dokeos, Claroline, etc. However, the most used tool, installed, customized and distributed in Higher Education Institutions is Moodle, Conde [8] mentions, the main reasons for its use: free software features, great global expansion, acceptance, and the ability to integrate with new technologies.

Similarly Adell, Castellet \& Gumbau [1] recommend using Moodle after analyzing similar tools, the reasons summarize below:

- Various educational options that let you work with some flexibility in a modular design, without limiting the different teaching styles.

- $\quad$ Being an open source tool allows support and continuous improvement, plus a free way.

- With Moodle can create Virtual Learning Environments and Virtual Environments for Teaching and Learning, depending on the context in which you are working.

- $\quad$ Also important are the new possibilities for integration with PLE (Personal Learning Environments). 


\subsection{Moodle}

Modular Object-Oriented Dynamic Learning Environment (Moodle) is an Open Source Course Management System, also known as a Learning Management System - LMS or a Virtual Learning Environment-VLE.

To Baumgartner [3], Moodle allows working in three models educational reference, the same as illustrated in Figure 1.

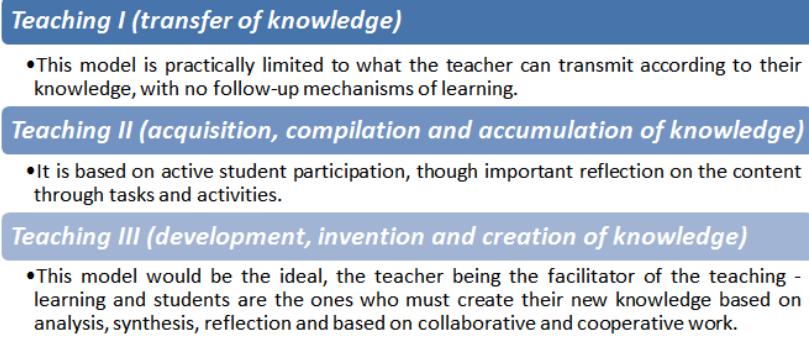

Figure 1. - Possible educational models recreated on Moodle. Compiled from information of Baumgartner [3].

In these possible models should emphasize the importance of the work of the teacher as mediator of these processes, as the technology itself does not generate learning, but simply provides the means to facilitate, in the teaching model 1, the platform would only reproduce inefficient environment that exists in conventional classrooms, but in the teaching model 3 , evidenced a breakthrough, since knowledge is not transmitted, but is created by the students, supported by the teacher and thanks to the advantage of the potential offered by Moodle.

\section{PERSONAL LEARNING ENVIRONMENTS}

The existence of a personal environment for learning is innate in man, who is in a continuous process of knowledge and throughout its life; the human being has always had an environment where learn [7]. From a historical standpoint, was first in the group, in the tribe or community. Subsequently, learning occurs with teachers, appears well master-apprentice relationship, educational environment present in many cultures and for many years.

The invention of printing, and thus the distribution of books, marks an important moment of change in the learning, which enables books become primary sources of information, and the built environment from these items were rated as unquestionable sources of knowledge.

Subsequently, these spaces learning are institutionalized, leading to what we call school and entire the responsibility of learning is attributed to it [7], even though the student continues to learn from other sources such as the social environment, family, etc.., but these means are not recognized as such.

As it can see, personal learning environments have always been present in human history, but with the massive adoption and implementation of ICT in most daily activities are increasingly inundated with information at all times is already evidence that the learning is not centralized, but it is influenced by multiple item types, resources, subject, context, etc.

The wide use of Web 2.0 tools in education and particularly in the university is a reality, supported also by the availability of interconnectivity and Internet access offering today's electronic devices such as laptops, netbooks, tablets, smart phones and other electronic devices that every day surprised to incorporate into their functionalities, storage capacities and access to networks.

In this dynamic, the students today access to content, they are called so because not all content is information [14], through various forms: search engines, social networks, SMS, virtual classrooms, etc. alternative sources of information and are also available to anyone, including breaking cultural and language barriers, where issues such as translations of pages, documents and resources are automatic and transparent to the user. However, these contents should be discussed, validated, cured and / or published.

Then these new systems formed by the sum of all resources, activities and elements in education, constitute the so-called personal learning environments, which according to researcher Salinas [19], is defined as: "A Personal Learning Environment is constituted by different systems that help students take control and manage their own learning. This includes support for: decide their own learning goals, managing their own learning, managing both content and process, communicate with others in the learning process and everything that contributes to achieving the objectives"

According to the above concept a PLE would not be a single system, but the fusion of many of them, enabling management objectives, content, time, taking advantage of the communication channels offered by ICT to support and support other environments.

If are reviewed other definitions, less pedagogical, it can be seen that the PLE could be understood more as an application of web-based software, to facilitate the organization of resources and the socialization of learning outcomes [20], or seen as integration of specific informatics tools such as weblog, ePortfolio, and social networks [18].

On the other hand, it has a fairly comprehensive proposal, made by Conde [8], who defined a PLE as:

"A learning environment focused on the user and customizable for him, which combines all the tools, services, opinions, people, resources and activities that are useful in the learning process. This environment must take into account the different types of 
training, facilitate learning throughout students' lives and allow the incorporation of new technologies. From a technological point of view can be defined as an integration framework that incorporates technologies 2.0 supports interaction with other learning contexts, facilitates the integration and compatibility with existing systems (such as repositories and LMS) and provides tracking systems for the students, as evidence of the activity"

In this definition, the PLE is seen even outside the areas that ICTs offer, and extends the social environment that influences the individual learning. As for the technical features highlights the contribution of Web 2.0 tools to educational processes and integration with other technologies and platforms that manage educational institutions which in turn allow us to document the evidence of learning.

However, the more general definition, cited in the introduction to this work is the proposal by Adell \& Castañeda who describe the PLE as "the set of tools, data sources, connections and activities that each person uses assiduously for to learn "[2]. This proposal emphasizes simplicity to understand the issue and that in turn serves as a starting point for detailing the parts that would have a basic PLE described in this paper.

\subsection{Basic Structure of a PLE}

After reviewing the article "Personal Learning Environments (PLEs): a new way of understanding learning" of Jordi Adell and Linda Castaneda [2], in a basic PLE include three types of tools and strategies: reading, reflexion and connection with others, the same authors [7], put special emphasis on the strategies, in terms of mechanisms and activities, and when referring to the tools involved in each of the PLE, are those that are included in the Web 2.0, as well as many free software alternatives that are currently available, whether they are to be installed on devices and computers, or to access the cloud (cloud computing).

In addition, as mentioned by the same authors "There are no tools or strategies or mechanisms that can be considered exclusive to a single part of the PLE" [7], thus the same tool or resource, could be used both for access information as well as to transform this information into knowledge through reflection and in turn be spaces to share and socialize content, as for example with the use that can be given to documents in Google Drive, with exposure and active participation in a videoconference or through blogs, to name some specific resources.

\subsection{Infrastructure of a PLE}

Having identified the parts of a PLE, and specified the tools, mechanisms and activities that allow us to access, process and share learning, it should identify the elements that are part of the infrastructure upon which to develop these environments.

According to Casquero [6], the idea of having a ideal PLE, would be that students are provided with a single gateway to all services that use and, once inside, and these technological scenarios are also unique , so as to ensure thus customizing the learning. This is now possible thanks to some technologies such as content syndication via RSS (Really Simple Syndication), which are formats for sharing content on the Web. This allows each student to select only the topics of interest of which receive continuous updates. Likewise, the PLEs of each student may be new information channels available for subscription.

The contents within these environments, according to criteria established by Casquero [6], could be structured through three types of content management systems: blogs, wikis and LMS, as each one of them allow building, publishing and updating information so that any changes are automatically reflected in the PLE through notifications. In addition, the contents shown could be supplemented with other digital resources specific pages or files as links, images, photographs, videos, audios, documents and presentations, the same as would be housed at specific sites for each resource, including: Delicious for bookmarks, Flickr for images, YouTube for videos, Slideshare for presentations and Scribd for documents [7], as well as online documents offering Google Drive.

When referring to relationships so necessary for information to flow in these settings properly, the network infrastructure needed to support a PLE should include nodes, connections between nodes and digital resources, they are born and stream, from and to the nodes (learnstreaming), where nodes would be represented by the digital identity of each student and the connections between them would set both school and particular interests [5].

\subsection{Integration with LMS}

These personal learning environments should be developed and strengthened to any educational level. However, let contextualize specifically in higher education, which is purpose of this study, from where it is observed that students have a resource specific technology that is now present in most higher education institutions, such as virtual classrooms managed through the LMS [17].

The scientific literature shows some attempts at rapprochement and integration of the LMS with PLE [12], thanks to some possible scenarios [21].

1. LMS and PLE parallel existence. - This corresponds to the way, as now is being carried the learning. On the one hand students access to virtual classrooms for each course, from where it manages part of their learning activities, such as access to resources, tasks, interests and evaluations, however it is true that also employ other resources outside these formal settings, similarly to access resources, process information and communicate with their peers, which for the author might consider as their PLE. It is understood that if he wants to become an ideal PLE could not have independence between LMS and PLE, since the virtual classrooms managed by the LMS are a fundamental part of every college student PLE, as confirmed by the definitions cited above [18, 19, 2, and 8].

2. Opening the LMS through the inclusion of Web services and interoperability initiatives. - In this second scenario, the LMS should make it possible to access from other tools or PLE managers, however the lack of openness in the design of the institutional platform to be accessed by third parties and the little interaction that would exist in the uni-directionality of information flow, cause the integration difficult. 
3. Integration of external tools in the LMS. - In this integration model, the selection of tools that are part of the PLE, depend from the LMS managers, who are responsible for the design and management of the same, which would limit the freedom of the student for choosing a particular resource, such examples could be the inclusion of social networks like Twitter in virtual classrooms.

It is considered important to emphasize that the successful integration of LMS, in personal learning environments have much to do with the flexibility, transparency and ease to give both the teacher and the student, and thus, exploit the potential offered by technologies, ensuring the application of these new learning models student centered [9].

\section{METHODOLOGY}

This research is quantitative and corresponds to a non-experimental study, that: "are made without the deliberate manipulation of variables and in which phenomena are observed only in their natural environment and then analyze" [13], and is transverse or transactional because the data collection process is applied in one moment and descriptive, because they are going to investigate the use of virtual classrooms as tools constitutive of PLEs of a group of college students.

The populations of this research work are the students of the career of Informatics Applied to Education, of National University of Chimborazo Ecuador (UNACH) who are studying in the annual mode. It is noteworthy that the career in question is in a process of changing from annual to semi-annual mode. When developing this study is in the annual mode, the third and fourth year, being your academic period from September to July. Have been chosen the courses in annual mode, due to that the date of application of the instrument have been working with virtual classrooms a considerable time (since September 2012) allowing their opinions to be more objective unlike courses semiannual mode, whom have started the new semester academic recently.

Students who attend regularly in the academic year September 2012 - July 2013, are shown in Table 1.

Table 1.- Students regularly attending the annual mode in the academic year 2012-2013. UNACH source.

\begin{tabular}{|l|c|}
\hline \multicolumn{1}{|c|}{ Level } & $\begin{array}{c}\text { Enrollment as regularly } \\
\text { attending }\end{array}$ \\
\hline Third Year & 17 \\
\hline Fourth Year & 24 \\
\hline Total & 41 \\
\hline
\end{tabular}

Also, being a small group, will work with the total population.

\section{RESULTS}

\subsection{About the information access tools}

In this part, we are interested in knowing their rating by students in virtual classrooms as a means of access to information and if this access also is given from the other resources.

So we have to, only $14.6 \%$ disagree that content (documents, presentations) exposed in virtual classrooms is enough, while most do agree that these resources are sufficient (46.3\%). If we analyze the ends, no student will answered that was totally disagree while $9.8 \%$ if are totally agreed. It is important to mention that $29.3 \%$ is indifferent to this question. We can see in the Table 2 .

Table 2.- Is there enough content (documents, presentations) exposed in virtual classrooms?

\begin{tabular}{|l|r|r|r|r|}
\hline & Frequency & \multicolumn{1}{c|}{$\begin{array}{c}\text { Valid } \\
\text { \% }\end{array}$} & $\begin{array}{c}\text { Accumulate } \\
\%\end{array}$ \\
\hline Total Disagree & 0 & 0 & 0 & 0 \\
\hline Disagree & 6 & 14,6 & 14,6 & 14,6 \\
\hline Indifferent & 12 & 29,3 & 29,3 & 43,9 \\
\hline Agree & 19 & 46,3 & 46,3 & 90,2 \\
\hline Total Agree & 4 & 9,8 & 9,8 & 100,0 \\
\hline Total & 41 & 100,0 & 100,0 & \\
\hline
\end{tabular}

Already on the job with virtual classrooms, want to know if you actually access all of the resources exposed, more than half of respondents (51.2\%) agreed that access to all content exposed, while a third of respondents to this question is indifferent to this question, and a cumulative percentage of $12.2 \%$ consider not access everything that is published in virtual classrooms. 
On the other hand, there are obviously other online electronic media that students use in their learning processes, where the $87.8 \%$ cumulative, respond agree and fully agree that you use other online tools to review information (Youtube, Wikipedia, forums, Slideshare, etc.) regarding the subjects that are not found in virtual classrooms.

In the Figure 1 shows a summary of the views of respondents in this category of questions.

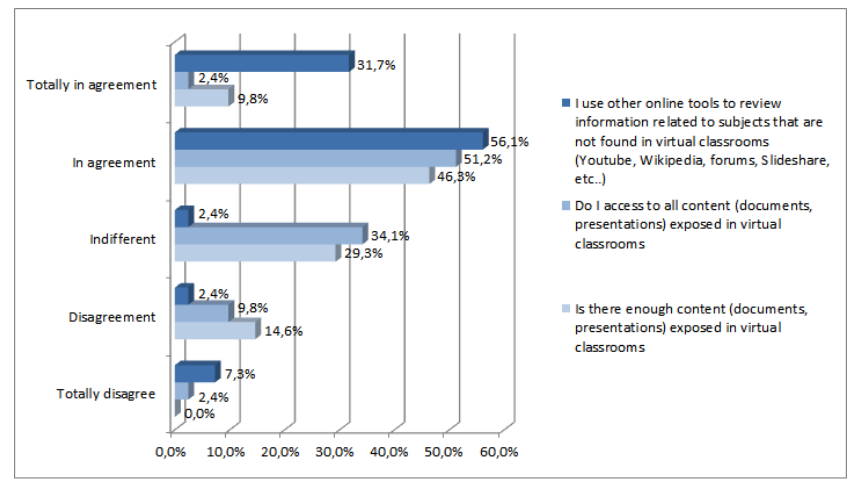

Figure 1.- Information access tools $(n=41)$.

\subsection{About the editing tools and publication of information}

Currently there are many Web 2.0 tools that allow both editing and publication of documents, presentations and multimedia resources, these resources are available from the cloud (cloud computing), which only requires a registration through an email account able to use and publish. This section of questions asks about the adoption of these tools in the group of students surveyed.

It is noted that more than $50 \%$ of the respondents (56.1\% cumulative) uses only programs installed on the computer to edit its contents, but is also seen that one in three respondents $(31.7 \%$ cumulative) in disagree or strongly disagree with this statement, which suppose that this group of students are using online tools for editing documents, presentations, videos, images, etc.

With regard to the question of what students use for publishing the content developed, $24.4 \%$ disagree and $7.3 \%$ fully disagree that the virtual classroom is the only way where they publish their content, yet more than half of respondents, which corresponds to a $51.2 \%$ cumulative, says that only socialize their work through the tasks, wikis, glossaries and forums of virtual classrooms.

But those students who do not publish the contents only through virtual classrooms, socialize information through other online resources as we can see that three of every four students (75.6\% cumulative) say they agree and strongly agree using online tools for editing and publishing content (documents, presentations, videos and images), that are not within virtual classrooms (Google Docs, Blogger, WordPress, YouTube, Flickr, SlideShare, Scribd, etc.) and only just $9.8 \%$ of students thinks otherwise.

In Figure 2 you can see a summary of the views of respondents in this category of questions.

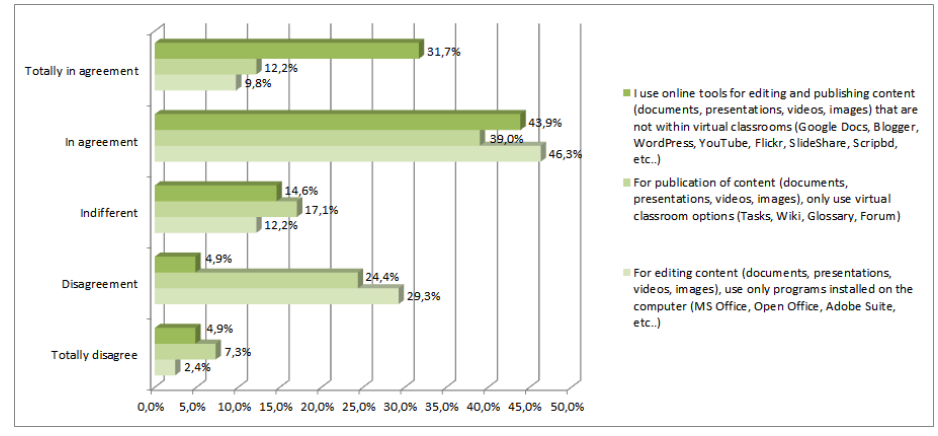

Figure 2.- Editing tools and publication of information $(n=41)$.

\subsection{About the relationship and communication tools}

This group of questions, investigates about the resources that students use for communication, where over $50 \%$ of students $(51.2 \%$ cumulative) uses channels as chat, messaging and forums of virtual classrooms, only for academic reasons, and just $9.8 \%$ of respondents this fully disagree with this statement.

Even about half of the respondents (48.8\% cumulative) believes that mandatory participation in virtual classrooms forums is the reason for use, and to a lesser extent by $31.7 \%$ participates without obligation in these channels communication, what for them demonstrates the usefulness of this type of resources.

For $82.9 \%$ (cumulative) of the students surveyed, it is very important to use social networks, chat, forums and other types of online resources as communication media for academic, since $51.2 \%$ of the respondents agree with the statement and $31.7 \%$ strongly agree, while 
only two respondents do not share this statement, which makes suppose that this small group of students not mix their online social spaces with their academic activities.

Figure 3 is a summary of the views of respondents in this category of questions.

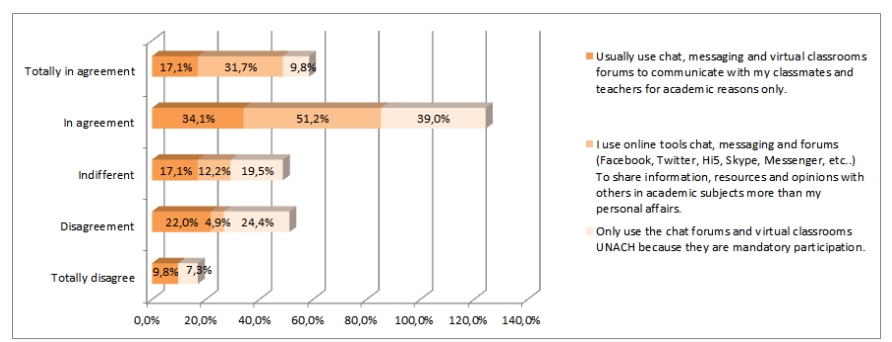

Figure 3.- Relationship and communication tools $(n=41)$.

\section{CONCLUSIONS}

From this study it can draw some important conclusions that, while it is true, by the nature of the investigation cannot be establish generalizations, but opens lines of research in the field of ICT for teaching and learning processes, specifically for the career of Informatics Applied to Education in the Faculty of Education Human Sciences and Technologies of National University of Chimborazo.

On the use of virtual classrooms, although $39 \%$ of students surveyed in this study, uses these virtual spaces outside the academic activities, most corresponding to $61 \%$ indicate that the use given to the same is strictly academic, to future invites to raise questions about, the effectiveness of this practice, the impact on academic performance, the quality of learning and motivation in educational processes.

The resources exposed in virtual classrooms, reason for this investigation, are considered sufficient for more than $50 \%$ of the students surveyed, although, they not accesses all of the resources exposed and uses other online tools (Youtube, Wikipedia, forums, Slideshare, etc.) to review information related to the subjects.

The desktop programs remain the most students use to perform their tasks, they are socialized through virtual classrooms, but also demonstrates the use of online tools for editing and publishing.

The use of communication tools that offer virtual classrooms are used mainly for strictly academic, and even, participation in forums and chats for all is not natural, but responds to extrinsic motivation seen as obligation; this could be, because a large number of respondents $(82.9 \%)$, use other online resources like social networks for academic activities.

Regarding the use of virtual classrooms as tools that constitute the Personal Learning Environments of the students surveyed, we can say that these virtual educational settings do allow access, editing and publishing much of academic information, as well as provide functionality communication and relationship, but also using other external tools, so it is concluded that the virtual classroom is an important part but not enough to structure the PLE.

Furthermore, although the majority of respondents believe that virtual classrooms only manage a part of their learning processes, inasmuch as another important part is given from outside, the criteria in the group is divided when you consider if this effort should be taken into account for evaluation, but, the vast majority of students participating in this study $(95.1 \%)$ fully agree, is in the ability to integrate Web 2.0 tools in virtual classrooms, which since it is a challenge for future projects of innovation and ICT integration in virtual learning environments.

It should also be noted that a large portion of the students surveyed (73.2\%) looks very interesting mobile access to virtual classrooms and web 2.0 tools as an aid to learning processes, which suggests that in a near future will increase the number of students who possess or have access to a device of this type, whose percentage in the present study is only $22 \%$ of students surveyed.

Finally, we are convinced that should design learning activities that promote the use, development and consolidation of the PLE and so take advantage of continuous innovations in information and communication technology.

\section{ACKNOWLEDGMENTS}

We would like to thank the Ministry of Science and Innovation of the Spanish Government for funding the project under identification number TIN2010-21695-C02-01, and the Regional Council of Education of Junta de Castilla y León (Spain) through the projects GR47 and MPLE (ref. SA294A12-2).

Similarly, we want to thank the Ministry of Higher Education, Science, Technology and Innovation of the Government of Ecuador (SENESCYT) and National University of Chimborazo (UNACH) for funding to perform this research.

This research work is made within University of Salamanca PhD Programme on Education in the Knowledge Society scope.

\section{REFERENCES}

[1] Adell, J., Castellet, J., and Gumbau, J., 2004. Selección de un entorno virtual de enseñanza/aprendizaje de código fuente abierto para la Universitat Jaume I. Castellón de la Plana: Centre d'Educació i Noves Tecnologies (CENT) de la Universitat Jaume I. 
[2] Adell, J., \& Castañeda, L., 2010. Los Entornos Personales de Aprendizaje (PLEs): una nueva manera de entender el aprendizaje. En R. \&. Roig Vila, Claves para la investigación en innovación y calidad educativas. La integración de las Tecnologías de la Información y la Comunicación y la Interculturalidad en las aulas. . Marfil - Roma TRE Universita degli studi.

[3] Baumgartner, P., 2005. Cómo elegir una herramienta de gestión de contenido en función de un modelo de aprendizaje. Retrieved from http://www.elearningeuropa.info/es/article/C\%C3\%B3mo-elegir-una-herramienta-de-gesti\%C3\%B3n-de-contenido-enfunci $\% \mathrm{C} 3 \% \mathrm{~B} 3 n$-de-un-modelo-de-aprendizaje?

[4] Cabero, J., 2006. Bases pedagógicas del e-learning. Revista de Universidad y Sociedad del Conocimiento (RUSC), 3,1-10.

[5] Casquero, O., Portillo, J., Ovelar, R., Benito, M., and Romo, J. 2010., iPLE Network: an integrated eLearning 2.0 architecture from University's perspective. Interactive Learning Environments, 293-308. doi: 10.1080/10494820.2010.500553

[6] Casquero, O., 2013. PLE: Una Perspectiva Tecnológica. En L. Castañeda, \& J. Adell, Entornos Personales de Aprendizaje: claves para el ecosistema educativo en red. Marfil, Alcoy, Spain, 71-84.

[7] Castañeda, L., and Adell, J., 2013. Entornos Personales de Aprendizaje: claves para el ecosistema educativo en red. Alcoy: Marfil.

[8] Conde, M., 2012. Personalización del aprendizaje: Framework de servicios para la integración de aplicaciones online en los sistemas de gestión del aprendizaje. Doctoral Thesis. University of Salamanca.

[9] Esteve Mon, F., and Gisbert, M., 2011. El nuevo paradigma de aprendizaje y las nuevas tecnologías. Revista de Docencia Universitaria, 9,55 - 73.

[10] García-Peñalvo, F., 2005. Estado actual de los sistemas e-learning. Teoría de la Educación: Educación y Cultura en la Sociedad de la Información, 6(2). Retrieved from http://campus.usal.es/ teoriaeducacion/rev numero $062 / \mathrm{n} 602$ art garcia penalvo.htm.

[11] García-Peñalvo, F., 2008. Advances in E-Learning: Experiences and Methodologies. London: IGI Global.

[12] García-Peñalvo, F., Conde, M., Alier, M., and Casany, M., 2011. Opening Learning Management Systems to Personal Learning Environments. Universal Computer Science, 17,1222-1240.

[13] Hernández, R., Fernández, C., and Baptista, M., 2010. Metodología de la investigación. McGraw-Hill, México D.F.

[14] Innerarity, D., 2011. La democracia del conocimiento. Paidós, Barcelona, Spain.

[15] Jolliffe, A., Ritter, J., and Stevens, D., 2001. The Online Learning Handbook. Routledge, New York.

[16] Moodle, 2013. Moodle. Retrieved (20 - 05, 2013) from https://moodle.org/sites/.

[17] Prendes, M. P., 2009. Plataformas de campus virtual con herramientas de software libre: Análisis comparativo de la situación actual en las universidades españolas. Retrieved from http://www.um.es/campusvirtuales/informe.html: Informe del Proyecto EA-2008-0257 de la Secretaría de estado de Universidades e Investigación.

[18] Razavi, M., and Iverson, L., 2006. A grounded theory of information sharing behavior in a personal learning space. CSCW' 06 Proceedings of the 2006 20th anniversary conference on Computer supported cooperative work, 459-468. doi: $10.1145 / 1180875.1180946$

[19] Salinas, J., 2008. Algunas perspectivas de los entornos personales de aprendizaje. TICEMUR 2008. III Jornadas NAcionales TIC y Educación, Lorca $(M U)$.

[20] Türker, M., and Zingel, S., 2008. Formative Interfaces for Scaffolding Self-Regulated Learning in PLEs. eLearning Papers, 1-15.

[21] Wilson, S., Liber, O., Johnson, M., Beauvoir, P., Sharples, P., and Milligan, C., 2007. Personal Learning Environments: Challenging the dominant design of educational systems. Journal of e-Learning and Knowledge Society, 3(2), 27-38.

[22] Zapata, M., 2003. Sistemas de gestión del aprendizaje - plataformas de teleformación. Revista de Educación a Distancia., de $\begin{array}{lllll}\text { Monográfico } & \text { I.- } & \text { Calidad } & \text { en } & \text { EAD. } / / \text { revistas.um.es/red/article/view/25661. }\end{array}$ 